\title{
Characteristics and Challenges of Agile Software Development Adoption in Brazilian Government
}

\author{
Rafaela Mantovani Fontana $a^{1}$ Sabrina Marczak ${ }^{2}$
}

\begin{abstract}
Governments worldwide have been working to provide better digital services to citizens. In Brazil, this initiative is ongoing since the 2000 's with the aim create better digital solutions that provide access to government information, improvements in public services, and increase social participation. One of the strategies for developing digital solutions - i.e. software solutions - is the adoption of agile software development (ASD) methods, which are forms of software processes that enable delivering working software in a timely manner to respond to customer needs. While industry surveys are performed annually to understand ASD adoption in companies, little is known about the adoption of ASD in Brazilian government organizations and which are the challenges faced by these organizations. The goal of this study is thus to describe agile software development adoption in the Brazilian public sector, by showing the characteristics for adoption and challenges. We conducted a survey with practitioners of government-based organizations in Brazil and statistically analyzed data. Out of the 167 responses, we learned that ASD projects are mostly successful and, on their majority, they are conducted combined with other software development approaches. Also, accelerating product delivery and increasing productivity are ranked as the main reasons for agile adoption, followed by cultural change and resistance to change as the main challenges still faced by Brazilian government IT organizations in the use of ASD.
\end{abstract}

Keywords: agile software development; government; public sector; Brazil; survey.

Submitted: March $4^{\text {th }}, 2020 /$ Approved: August $25^{\text {th }}, 2020$

\section{Introduction}

Government organizations exist to provide services citizens (Lappi \& Aaltonen, 2017). Today's information era has led to the recognition that Information Technology (IT) investments are important for the development of capabilities and strategies (Malaquias \& Albertin, 2018). In the public sector, investments in IT enable governments to be connected and available, responding faster to citizen needs (Mergel, Gong \& Bertot, 2018). To reach such digitalized services, governments around the world are transforming their policies and structures in a movement called e-government (Lappi \& Aaltonen, 2017). In the Brazilian government this reality is not different. The most recent initiative was the creation of the Digital Governance Strategy. E-government initiated in Brazil in 2000 and strategies were most recently reviewed in 2018 with the aim to integrate digital transformation initiatives. These initiatives provide access to government information, improvements in public services and increase social participation. Their implementation are mostly based on the creation of digital platforms that give access to public information and services (Brazil, 2018).

Historically, governments develop these digital platforms using software processes based on "big design up front", as full specification of requirements have to be agreed upon before actual development starts. Nevertheless, this strategy has brought negative experiences and management failures (Mergel, 2016). To be able to innovate in the development of digital solutions governments worldwide are using agile software development (ASD) (Dyngsøyr et al., 2012).
While industrial surveys are performed annually to understand ASD adoption in companies (Version One, 2017), little is known on how is agile adoption in Latin America (Quelal, Villavencio \& Mendoza, 2018) and, specifically, how ASD is being adopted in Brazilian government organizations. Actually, agile adoption has been slower in public sector than in private sector (Ribeiro \& Domingues, 2018). There are evidences that the challenges faced by governmental organizations are similar to those faced by private organizations, but with additional complexity because of the characteristics of governmental organizations (Nuotilla, Alltonen \& Kujala, 2016), such as the presence of hierarchical and bureaucratic structures (Vacari \& Prikladnicki, 2015).

Our research question, in this study, is based on this gap and is as follows: "What are the characteristics and challenges of agile adoption in Brazilian government organizations?". Our goal is therefore to describe agile software development adoption in Brazilian Public Sector, focusing on characteristics and challenges faced by practitioners. We conducted a survey which received response by 167 practitioners from government organizations in Brazil. Our results show a big picture of ASD adoption in government organizations.

The remainder of this paper is organized as follows. Section 2 describes related work. Section 3 presents the research method and Section 4 reports on the survey results. Section 5 discusses the findings and concludes the paper.

(1)Department of professional and Technological Education, Federal University of Paraná, Brazil.

(2) School of Technology, Pontifical Catholic University of Rio Grande do Sul, Porto Alegre, Brazil.

${ }^{*}$ Corresponding author: rafaela.fontana@ufpr.br 


\section{Agile Software Development and Government}

Literature in recent years has been describing the adoption of agile software development approaches in government entities, which pose specific challenges, as ASD best suits organizational structures that are not hierarchical and bureaucratic (Vacari \& Prikladnicki, 2015). Research has been mainly empirical, through case studies, interviews-based studies and action research describing strategies for ASD adoption (Mergel, Gong \& Bertot, 2018). Studies in different countries show similar characteristics and challenges for agile adoption, as shown next.

In the United States, Patanakul \& Rufo-Mccarron (2018) conducted interviews and identified the challenges faced during agile transition. In Finland, Lappi \& Aaltonen (2017) studied project governance in the public sector in the context of agile projects. They studied three case public organizations and showed the challenges faced. Nuotilla, Aaltonen \& Kujala (2016), in another Finish study, also focused on the challenges.

The study by Mohaghegui \& Jørgensen (2017) describes the result of various interviews in Norwegian public sector agencies. In Portugal, Ribeiro \& Domingues (2018) identified a positive acceptance of agile methodologies in a public company, and Torrecillas-Salinas et al. (2013), in Spain, concluded that the agile approach seems to work better in small and experienced teams. Hajjdiab \& Taleb (2011) describe a failed agile adoption in the United Arab Emirates government entity. In Thailand, similarly, Wisitpongphan and Khampachua (2016) verified that challenges related to requirements and stakeholders.

In Brazil - the object of our study - Santos and Canedo (2014) present the challenges faced and benefits of agile adoption in a case study. Siqueira et al. (2018) describe the means by which continuous delivery contributed to developing trust in a large-scale government organization in Brazil. Sousa et al. (2016) describe an experience with Scrum in an outsourced Brazilian government project. Vacari \& Prikladnicki (2017) present a multiple-cases study that showed, in Brazil, challenges and improvements with agile methods. The same authors, in a previous literature review identified a bias towards prescriptive approaches and big bang deliveries in public sector (Vacari \& Prikladnicki, 2015). The only survey we found on governments ASD adoption was the one by Quelal, Villavencio \& Mendoza (2018), which shows consolidated results of 31 practitioners.

As the most part of studies describe specific cases, our goal here is to complement current findings, providing a broader view, through a survey, to a get a big picture of agile adoption in Brazilian government.

\section{Method}

The goal of this study is therefore to describe the characteristics and challenges of agile software development adoption in Brazilian public sector. We applied a survey as the research method, as it is a method for "collecting information to describe, compare or explain knowledge, attitudes and behavior" (Pfleeger \& Kitchenham, 2001, p. 16). We applied the steps suggested by Pfleeger \& Kitchenham (2001) to design and conduct a survey as follows.
- Setting specific, measurable objectives: As mentioned before, our goal is to describe characteristics and challenges of ASD adoption in Brazilian public sector. The characteristics are described by agile method use, reasons for adopting, and success and impacts of ASD adoption. The challenges faced during agile adoption get a specific attention in current literature. To verify these challenges, we defined five hypotheses to be verified in our data. The hypotheses were based in the authors described in Section 2:

- H1. The challenge on cultural change is relevant when compared to the other challenges.

- H2. The challenge on customer collaboration is relevant when compared to the other challenges.

- H3. The challenge on competences and knowledge development is relevant when compared to the other challenges.

- H4. The challenge on bureaucracy and existing processes is relevant when compared to the other challenges.

- H5. The challenge on top management support is relevant when compared to the other challenges.

- Planning and scheduling the survey: The survey was conducted in three different Brazilian industry-focused conferences during 2018: Agile Trends in São Paulo, Agile Brazil in Campinas and Agile Trends Gov in Brasília. Questionnaires were printed and randomly distributed to conferences' attendees who welcomed our face-to-face invitation to participate in our study.

- Ensuring the appropriate resources are available: Before conducting the data collection, we contacted the chairs of the conferences and asked for authorization to approach attendees to participate in the research.

- Designing the survey and preparing the data collection instrument: We designed the questionnaire based on eight different questionnaires for agile surveys available in literature: Azizyan et al. (2011); Rodriguez et al. (2012); Melo et al. (2013); Bustard et al. (2013); Diel et al. (2015); Version One (2017); Bollati et al. (2017); and Kuhrmann et al. (2018). These studies described industry-based questionnaires. We compared their original questions and selected the most relevant questions to the agile government context. As our plan was to apply the questionnaire in printed form, the number of questions was limited to an answering time of 10 minutes maximum.

- Validating the instrument: We validated the instrument with three researchers - full time professors of the institutions involved in this study. We also validated with one of the involved conference's chairs, which is an experienced practitioner. They answered our questions and gave feedback on time of answering, form and organization, and comprehension of the questions.

- Selecting participants and administering and scoring the instrument. As mentioned before, the questionnaires were printed out and distributed to conferences' attendees. We hired four people in each event - public relationship professionals. They were trained before the conference by the research coordinator (first author) and randomly approached people participating in the conference 
to answer the questionnaire. They distributed the questionnaire forms and waited for them to be filled up and handed back in hands. We did not perform any validations on data during this collection due to the effort necessary for distributing and receiving back the forms. The research coordinator followed all the operation, answering to any questions the participants eventually asked. After the conferences, all responded forms were individually checked for completion and transcribed to a sheet for analysis.

- Analyzing data: We analyzed data using descriptive analysis, through frequencies and percentages. Hypotheses were verified using confidence intervals.

\subsection{Threats to validity}

The main threat to the validity of our study is the convenience sample (Fricker Jr., 2016) - as participants were those who participated in the conferences. It may not be significantly representative of the whole population of Brazilian government practitioners. Nevertheless, the results of the survey might be used for further comparison with future studies that may - or may not - confirm our results. Next section describes these results.

\section{Results}

We collected 167 responses from agile government practitioners. The latest research in Brazilian information technology employment (Softex, 2019) has shown that in 2017 we had 415,166 people employed in the information technology field. From these, the research shows that $19.9 \%$ were in public sector. It means that our estimated population is of 82,618 people. Thus, our sample represents $0.2 \%$ of the population. All of our respondents reported to work with government and public services in different contexts (education, software, financial services, telecommunications, health and others). They were $72.2 \%$ male and $22.75 \%$ female respondents, $50 \%$ of them located in the government state (Federal District) in Brazil and others distributed in other 13 states. Their age ranged from less or equals to 25 years old (0.6\%), 26 to 35 years old (40.1\%), 36 to 45 years old (49.1\%), and older (10.2\%).

Their experience with software development was less than a year for $4.3 \%, 1$ to 2 years of experience for $4.3 \%, 2$ to 5 years for $9.1 \%$ of participants, 5 to 10 years to $21.3 \%$ of them, 10 to 20 years to $43.9 \%$ of them and more than 20 years to $17.1 \%$. Regarding their experience with agile methods, $15 \%$ reported to have little knowledge, $66.5 \%$ reported to have moderately experienced, $14.4 \%$ reported to be very experienced and $1.2 \%$ stated they are extremely experienced.

Respondents also reported the size of their organizations, which were $0.6 \%$ with less than 9 employees, $2.4 \%$ with 10 to 49 employees, $0.6 \%$ with 50 to 99 employees, $13.9 \%$ with 100 to 999 employees and $82.5 \%$ with more than 1000 employees. When argued about their teams' sizes, respondents pointed out that $11.1 \%$ had teams with less than six people. Teams with 6 to 10 people were $16 \%$, with 11 to 20 people were $19.8 \%$, with 21 to 50 people $13.6 \%$, and $39.5 \%$ with more than 50 people.

Regarding the range of time their companies have been using agile methods, $12.8 \%$ reported to be less than a year, $25.0 \%$ reported to be
1 to 2 years of agile methods use, $38.4 \%$ reported 3 to 5 years, $18.9 \%$ reported 6 to 10 years and the minority (4.9\%) reported to use agile methods for more than 10 years.

\subsection{Characterization of Agile Methods Usage}

The first question we applied to identify how agile methods have been used in Brazilian government asked which methods practitioners use. Table 1 reports our results showing that Scrum and Kanban are the most used methods, with $73.1 \%$ and $58.1 \%$ of use, respectively. A customized method according to the company' need was the third most cited response (18.6\% of respondents). Respondents could give more than one answer and we show here the ten top methods.

Table 1. Percentage of respondents that reported to use each agile method. These are the ten top methods. Cronbach alpha for this question was 0.45 .

\begin{tabular}{lc}
\hline Agile Method & Percentage of respondents (\%) \\
\hline Scrum & 73.1 \\
Kanban & 58.1 \\
Hybrid customized & 18.6 \\
Iterative development & 18.6 \\
Scrum/XP hybrid & 15.6 \\
XP & 15.0 \\
Lean Development & 10.8 \\
Scrumban & 10.2 \\
Lean Startup & 5.4 \\
Others & 12.6 \\
\hline
\end{tabular}

When argued whether they combined the agile method with a more traditional one, such as Waterfall or Unified Process, respondents on the majority (61.1\%) said that yes, they combine agile and traditional methods. Other $32.3 \%$ of the respondents reported that they do not combine agile with other approaches and $6.6 \%$ reported not to know. Table 2 reports on the adopted practices. The respondents could indicate more than one answer to this question. We show here the ten top practices. We see Kanban and Daily standup meetings as the most mentioned ones.

Table 2. Percentage of respondents that reported to use each agile practice This table shows the ten top ones. Cronbach alpha for this question was 0.88 .

\begin{tabular}{lc}
\hline Practices Adopted & Percentage of respondents (\%) \\
\hline Kanban & 69.6 \\
Daily standup & 63.6 \\
Sprint/iteration planning & 60.5 \\
Short iterations & 59.0 \\
Continuous integration & 56.8 \\
Single team (integrated dev and test) & 56.2 \\
Retrospectives & 54.3 \\
Team estimation & 52.5 \\
Releases planning & 51.2 \\
User story mapping & 49.4 \\
\hline
\end{tabular}

We also asked respondents on the reasons for which their companies have adopted agile methods. Table 3 shows that the main reason for 
being agile is accelerating product delivery. The least mentioned reason is for the management of distributed teams. Respondents could choose more than one answer.

Table 3. Government organizations' reasons for adopting agile methods, according to respondents. Cronbach alpha for this question was 0.68 .

\begin{tabular}{lc}
\hline Reasons for adopting agile methods & Percentage of respondents (\%) \\
\hline Accelerate software delivery & 77.1 \\
Increase productivity & 63.9 \\
Enhance ability to manage changing & 42.8 \\
priorities & 39.0 \\
Reduce project risk & 35.2 \\
Enhance software quality & 33.9 \\
Enhance delivery predictability & 32.3 \\
Improve business/IT alignment & 24.7 \\
Improve team morale & 23.6 \\
Improve project visibility & 21.2 \\
Reduce project cost & 19.3 \\
Increase software maintainability & 19.3 \\
Improve engineering discipline & 11.4 \\
Better manage distributed teams & 3.6 \\
Do not know & 3.0 \\
Other &
\end{tabular}

Our questionnaire also included questions on the projects' success. Agile projects were successful for $50.3 \%$ of respondents, $6.7 \%$ said that they were not and $39.3 \%$ mentioned that sometimes projects are well succeeded. From the respondents, 3.7\% reported not to know.

We also asked about the impact of agile adoption on Brazilian Government companies. Respondents should evaluate each aspect described and respond whether this aspect has improved, had no effect or has got worse. Figure 1 shows the percentage of respondents for each aspect and impacts mentioned. Team collaboration and team communication were the most improved aspects. The less improved ones were on managing distributed teams and engineering discipline. The aspect that most got worse according to respondents (9\%) was project predictability.

\subsection{Challenges faced during agile adoption}

To verify the challenges faced in agile adoption in Brazilian governments, we analyzed their relevance based on confidence intervals (CI 95\%). Table 4 shows the confidence interval and the percentage of respondents for each challenge. To be considered relevant, a challenge should not share its confidence interval with at least half of other challenges. Our hypothesis were:

Figure 1. This graph shows how was the impact on each aspect, from the one that most improved to the less improved. Numbers represent the percentage of respondents. Cronbach alpha for this question was 0.93

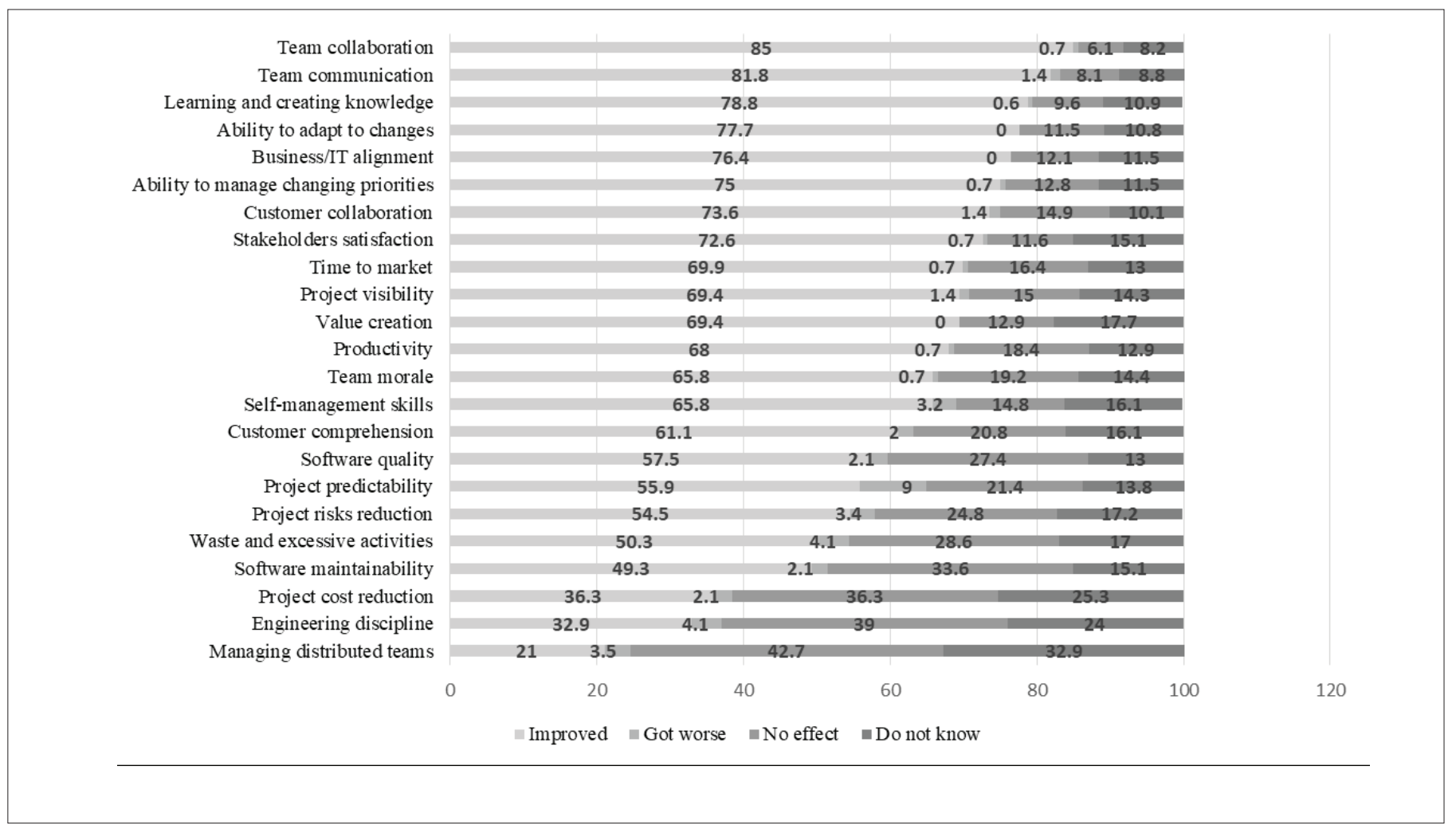


- H1. The challenge on cultural change is relevant when compared to the other challenges: When analyzing Table 4, we see that cultural change interval only coincides with resistance to change interval. It confirms our hypothesis 1 .

- H2. The challenge on customer collaboration is relevant when compared to the other challenges. By comparing customer collaboration interval with other challenges, we see that it does not coincide with other 15 challenges, from the 20 challenges listed. It thus confirms that customer collaboration is a relevant challenge, confirming our hypothesis 2 .

- H3. The challenge on competences and knowledge development is relevant when compared to the other challenges. Hypothesis 3 can be verified with items "Inadequate training", "Steep learning curve" and "Need for special skills". Inadequate training is only more relevant than two other challenges. "Steep learning curve" and "Need for special skills" are not more relevant than any other one. This hypothesis is thus not confirmed.

- H4. The challenge on bureaucracy and existing processes is relevant when compared to the other challenges. Hypothesis 4 is verified based on the confidence intervals for the items "Translating agile principles from development to business", "Fixed price contracts", "Inadequate documentation" and "Inadequacy of existing technologies and tools". For the first one, it is more relevant than seven other challenges. Fixed price contracts, is more relevant than five other challenges and Inadequate documentation than only two other challenges. These evidences thus do not confirm hypothesis 4 .

- H5. The challenge on top management support is relevant when compared to the other challenges. Hypothesis 5 is verified based on the "Top management commitment" confidence interval. As it is more relevant than other 14 challenges, we consider it relevant. It confirms our hypothesis 5. Relevant challenges are underlined in Table 4.

Table 4. Challenges faced in agile adoption. Cronbach alpha for this question was 0.52

\begin{tabular}{|c|c|c|}
\hline Challenges faced in agile adoption & Confidence Interval (95\%) & Percentage of respondents (\%) \\
\hline Cultural change & $60.9 \%-75.3 \%$ & 68.1 \\
\hline Resistance to change & $48.8 \%-64.1 \%$ & 56.4 \\
\hline Customer collaboration & $43.9 \%-59.2 \%$ & 51.5 \\
\hline Top management commitment & $40.2 \%-55.5 \%$ & 47.9 \\
\hline Defining business value & $26.5 \%-41.0 \%$ & 33.7 \\
\hline Fixed price contracts & $22.0 \%-36.0 \%$ & 29 \\
\hline Measuring agile success & $18.5 \%-31.8 \%$ & 25.5 \\
\hline Inadequate training & $15.7 \%-28.5 \%$ & 22.1 \\
\hline Inadequate documentation & $11.9 \%-23.7 \%$ & 17.8 \\
\hline Agile methods scaling & $11.4 \%-23.0 \%$ & 17.2 \\
\hline Activities synchronization & $7.2 \%-17.3 \%$ & 12.3 \\
\hline Loss of management control & $4.3 \%-12.9 \%$ & 8.6 \\
\hline Inadequacy of existing technologies and tools & $2.9 \%-10.6 \%$ & 6.8 \\
\hline Need for special skills & $2.5 \%-9.8 \%$ & 6.1 \\
\hline Other & $0 \%-3.9 \%$ & 1.8 \\
\hline
\end{tabular}

\section{Discussion}

The goal of this study was to describe agile software development adoption in Brazilian public sector. We conducted a survey in industry-focused conferences and received 167 responses from government practitioners. Our results showed the characteristics of ASD adoption (methods, practices, reasons, impacts) and also verified the challenges for agile adoption in Brazilian public sector context.

We learned that Scrum and Kanban are the most used agile methods, although more than half of practitioners say that they mix agile methods with more traditional ones (as stated by Kuhrmann, 2017). Kanban and daily standup are the most used agile practices. The top reasons for agile adoption are accelerating software delivery and increasing productivity. Regarding the impact of agile adoption, improvements were best identified in team collaboration, team communication, learning and creating knowledge. The aspect that most suffered with agile adoption, according to the respondents, was project predictability. Nevertheless, about half or respondents said that their projects based on ASD are successful. The relevant challenges we identified were cultural change, resistance to change, customer collaboration, and top management commitment. 
Our data consolidate the perception of multiple respondents, in different states of Brazil. Much of our results confirm the results from literature that describe specific case studies and literature reviews in Brazil. For example, Santos and Canedo (2014) described challenges on cultural change - also identified by Sousa (2016) - and lack of top management, which were confirmed as relevant in our data. The benefits of fast responses to requirement changes, early deliveries of main features and improved customer collaboration identified by these authors also appeared in our data, although as not the main reported ones.

Bureaucracy and competences, and knowledge development were challenges identified by Vacari and Prikladnicki (2017). In our data, these challenges appeared, but not as relevant when compared to others. Some of the benefits these authors identified, however, such as improved alignment between IT team and business people, communication and team improvement, increased customer satisfaction, and improvement in learning new technologies also appeared as the most improved aspects in ASD adoption in our results.

Our data show that ASD is a reality in government organizations in Brazil, not only in small teams, as stated in Spain by Torrecillas-Salinas (2013). The benefits are being realized and ASD adoption may actually be a strategy to create better digital solutions for citizens in e-government programs. Although our results are limited to the context of the sample respondents, they provide data for academics and practitioners to have a picture of ASD adoption in Brazilian government. Our results also give foundation for open research questions in future research. Further studies should address, for example, which are the strategies adopted to deal with cultural change in government ASD adoption, which are the factors that trigger top management involvement in government institutions to support ASD initiatives, and how bureaucracy is replaced when light-weighted ASD practices are in place. Last, but not least, new studies could show the relationship of ASD adoption to citizens' satisfaction on government digital products.

\section{Acknowledgments}

This project was supported by the Brazilian National Council for the Technological and Scientific Development (CNPq), through the process number 408976/2016-0.

\section{References}

Azizyan, Gayane; Magarian, Miganoush Katrin; Kajko-Matsson, Mira. (2011) Survey of Agile Tool Usage and Needs. In: Proceedings of the 2011 Agile Conference. 7-13 Aug. https://doi.org/10.1109/AGILE.2011.30

Bollati, Verónica A.; Gaona, Germán; Pletsch, Liliana Cuenca; Gonnet, Silvio; Leone, Horacio. (2017) The state of agile development adoption in Argentine software companies. In: Proceedings of the 2017 XLIII Latin American Computer Conference (CLEI). 4-8 Sept. https:// doi.org/10.1109/CLEI.2017.8226394

Brazil. (2018) Estratégia de Governança Digital: Transformação Digital - cidadania e governo/Ministério do Planejamento, Desenvolvimen- to e Gestão, Secretaria de Tecnologia da Informação e Comunicação. Available at https:/www.governodigital.gov.br/EGD/documentos/ revisao-da-estrategia-de-governanca-digital-2016-2019.pdf

Bustard, David; Wilkie, George; Greer, Des. (2013). The Maturation of Agile Software Development Principles and Practice: Observations on Successive Industrial Studies in 2010 and 2012. In: Proc. of the International Conference and Workshops on Engineering of Computer Based Systems (ECBS). 22-24 April. https://doi.org/10.1109/ ECBS.2013.11

Diel, Elisa; Bergmann, Mariana; Marczak, Sabrina; Luciano, Edimara. (2015). What is Agile, Which Practices are Used, and Which Skills are Necessary according to Brazilian Professionals: Findings of an Initial Survey. In: Proc. of the 2015 6th Brazilian Workshop on Agile Methods (WBMA). 22-22 Oct. https://doi.org/10.1109/ WBMA.2015.10

Dingsøyr, T.; Nerur, Sridhar; Balijepally, V.; Moe, N. B. (2012). A decade of agile methodologies: Towards explaining agile software development. Journal of System and Software. Vol. 85. No 6. pp. 1213-1221. https://doi.org/10.1016/j.jss.2012.02.033

Hajjdiab, H.; Taleb, A. S. (2011). Agile Adoption Experience: A Case Study in the U. A. E. In Proc of the IEEE 2nd International Conference on Software Engineering and Service Science. pp. 31-34. https://doi. org/10.1109/ICSESS.2011.5982247

Kuhrmann, Marco et al. (2017). Hybrid Software and System Development in Practice: Waterfall, Scrum, and Beyond. In: Proceedings of the ICSSP'17, Paris, France. https://doi. org/10.1145/3084100.3084104

Lappi, Teemu; Aaltonen, Kirsi. (2017). Project governance in public sector agile software projects. International Journal of Managing Projects in Business, Vol. 10 Issue: 2, pp.263-294, https://doi.org/10.1108/ IJMPB-04-2016-0031.

Malaquias, Rodrigo Fernandes; Albertin, Alberto Luiz. (2018) The Value of Being Innovative in Information Technology. Journal of Information Technology Management and Innovation. Vol. 13. No. 1. https://doi.org/10.4067/S0718-27242018000100003

Melo, Claudia de O.; Santos, Viviane; Katayama, Eduardo; Corbucci, Hugo, Prikladnicki, Rafael, Goldman, Alfredo; Kon, Fabio. (2013). The evolution of agile software development in Brazil. Journal of the Brazilian Computer Society. v. 19. pp. 523-552. https://doi. org/10.1007/s13173-013-0114-x

Mergel, I.; Gong, Y.; Bertot, J. (2018). Agile government: Systematic literature review and future research. Government Information Quarterly. vol 35. pp. 291-298. https://doi.org/10.1016/j.giq.2018.04.003

Mergel, I. Agile innovation management in government: A research agenda. (2016). Government Information Quarterly. vol. 33. n. 3. pp. 516-523. https://doi.org/10.1016/j.giq.2016.07.004 
Mohagheghi, P.; Jørgensen, M. (2017). What contributes to the success of IT projects? Success factors, challenges and lessons learned from an empirical study of software projects in the Norwegian public sector. In Proceedings of the International Conference on Software Engineering Companion. pp. 37-373. https://doi.org/10.1109/ ICSE-C.2017.146

Nuotilla, J.; Aaltonen, K.; Kujala, J. (2016) Challenges of adopting agile methods in a public organization. International Journal of Information Systems and Project Management. Vol 4. No. 3. pp. 65-85. https://doi.org/10.12821/ijispm040304

Patanakul, Peerasit; Rufo-Maccarron, Reneé. (2018). Transitioning to agile software development: Lessons learned from a government-contracted program. Journal of High Technology Management Research. IN PRESS. https://doi.org/10.1016/j.hitech.2018.10.002

Pfleeger, S, L.; Kitchenham, B. A. (2001). Principles of Survey Research. Part 1: Turning Lemons into Lemonade. ACM SIGSOFT Software Engineering Notes. vol 26. no. 6. pp. 16-18. November.

Quelal, R.; Villavicencio, M.; Mendoza, L. (2018). A Survey of Agile Software Development Methodologies in Ecuador. In Proceedings of the 13th Iberian Conference on Information Systems and Technologies (CISTI). June. https://doi.org/10.23919/CISTI.2018.8399186

Ribeiro, A.; Domingues, L. (2018). Acceptance of an agile methodology in the public sector. Procedia Computer Science, 138, pp. 621-629. https://doi.org/10.1016/j.procs.2018.10.083

Rodríguez, Pilar; Markkula, Jouni; Oivo, Markku; Turula, Kimmo. (2012). Survey on agile and lean usage in Finnish software industry. In: Proceedings of the 2012 ACM-IEEE International Symposium on Empirical Software Engineering and Measurement. 20-21 Sept. https://doi.org/10.1145/2372251.2372275

Fricker Jr, R. D. (2016). Sampling Methods for Online Surveys. The SAGE Handbook of Online Research Methods, page 162.

Santos, V. S. A.; Canedo, E. D. (2014). Metodologia ágil no desenvolvimento de Software - Estudo de Caso: Justiça Eleitoral do Brasil. CISTI (Iberian Conference On Information Systems \& Technologies), 111.
Siqueira, R.; Camarinha, D.; Wen, M.; Meirelles, P.; Kon, F. (2018). Continuous Delivery: Building Trust in Large-Scale, Complex Government Organization. IEEE Software. v. 35, issue 2. March/April. pp. 38-43. https://doi.org/10.1109/MS.2018.111095426

Softex. (2019). Overview do Setor de TI Brasileiro nos Últimos Dez Anos. Technical Report. Available in https://softex.br/download/ overview-do-setor-de-tecnologia-da-informacao-brasileiro-nos-ultimos-dez-anos/

Sousa, T.; Venson, E.; Figueiredo, R. M. C.; Kosloski, R. A.; Ribeiro Jr, L. C. M. (2016). Using Scrum in Outsourced Government Projects: An Action Research. In Proceedings of the 2016 49th Hawaii International Conference on System Sciences (HICSS). 5-8 Jan. https://doi. org/10.1109/HICSS.2016.672

Torrecillas-Salinas, C. J.; Sedeño, J.; Escalona, M. J.; Mejías, M. (2013). Agile in Public Administration: Oxymoron or reality? An experience report. CEUR Workshop Proceedings.

Vacari, I.; Prikladnicki, R. (2015). Adopting Agile Methods in the Public Sector: A Systematic Literature Review. In: Int'l Conf. on Software Eng. and Knowledge Engineering. 27. Pittsburgh University. https://doi.org/10.18293/SEKE2015-159

Vacari, I.; Prikladnicki, R. (2017). An Empirical Study on the Adoption of Agile Software Development in Public Organizations. In: Proceeding of the Brazilian Workshop on Agile Methods (WBMA 2016). Communications in Computer and Information Science, vol 680. Springer, Cham. https://doi.org/10.1007/978-3-319-55907-0_1

Version One. (2017). The $11^{\text {th }}$ Annual State of Agile Report. Available at versione.com.

Wisitpongphan, N.; Khampachua, T. (2016). Agile in public sector: Case study of dairy farm management projects. In: Proceedings of the 13th International Joint Conference on Computer Science and Software Engineering (JCSSE). 13-15 July. https://doi.org/10.1109/ JCSSE.2016.7748916 
